\title{
Please mind the gappy content
}

\author{
Johan Gersel ${ }^{1}$
}

Published online: 6 December 2017

(C) The Author(s) 2017. This article is an open access publication

\begin{abstract}
Representationalist theories of experience face the problem that two sets of compelling intuitions seem to support the contrary conclusions that we should ascribe, respectively, singular contents and general contents to experience. Susanna Schellenberg has, in a series of articles, argued that we can conserve both sets of intuitions if we award a central explanatory role to the notions of gappy-contents and content-schemas in our theory of experience. I argue that there is difficulty in seeing how gappy-contents and content-schemas can fulfil the explanatory role envisioned for them by Schellenberg. The central problem is that both gappycontents and contentschemas lack truth-conditions. Schellenberg attempts to support her view by suggesting an analogy between the role of content-schemas in our account of experience and the role of Kaplan's notion of character in our account of demonstrative statements. However, I show that this analogy breaks down at crucial places when it is explored in detail. Hence, gappy-contents and content-schemas cannot fill the explanatory roles that the representationalist awards to fully truthevaluable contents. Therefore, Schellenberg's theory provides no way for the representationalist to conserve both sets of competing intuitions.
\end{abstract}

Keywords Gappy content · Experience $\cdot$ Hallucination $\cdot$ Content-schema $\cdot$ Singular thought · Perceptual justification · Susanna Schellenberg · Representational theory of experience $\cdot$ Experiential content

Johan Gersel

jgersel@gmail.com

1 University of Vienna, Vienna, Austria 


\section{Introduction}

When we perceive we are aware of our surroundings, and this awareness provides us with experiential evidence. The representational theory of perception explains both these features in terms of the attribution of representational content to our experiential states. Our basic understanding of content comes from theories of speech and judgement. Thus, the representational theory of perception gets a lot of its appeal from relying on a basic analogy between perceiving, judgement, and testimony. I become aware that that tree is blossoming when this is represented to me through testimony, such as when Tod says to me 'that tree is blossoming'. Likewise, I become aware that that tree is blossoming when this is represented to me through perception. What I become aware of and what judgements I acquire evidence for is in both cases explained in terms of the content of, respectively, the statement and my perceptual state.

Crucially, the fact that that I hear a statement with a certain content is insufficient for me to acquire testimonial awareness and evidence. To do so, I must also possess sufficient linguistic understanding to understand the content of the statement. Likewise, it is insufficient for a subject to possess perceptual awareness and evidence that his perceptual system is in a content-bearing state. The subject must also appreciate the content of his state in some way. The common assumption is that such appreciation occurs when the world seems a certain way to the subject. In ordinary experiential cases, the world seems to me a certain way, and my perception represents the world as being precisely how it seems to me to be. Any further content the experience might possess which isn't reflected in how the world seems to me will neither figure as what I am aware of, nor influence the experiential evidence I possess. ${ }^{1}$

The ordinary representational theory of perception thus acknowledges the following connections between seemings, awareness, experiential content, and experiential evidence: ${ }^{2}$

1. How the world seems to me is a matter of what content my experience has. ${ }^{3}$

2. When the world seems to me a certain way, I have experiential evidence for judgements whose content is suitably related to the content of the experience that explains how the world seems to me.

3. To be perceptually aware of the world is to be aware that the world is as it seems to me; that is, I am aware that the world is as my experience represents it as being.

\footnotetext{
${ }^{1}$ The phenomenon of blind sight is often explained precisely by claiming that the blind sighted subject has visual states with a certain content, but lacks awareness and ordinary experiential evidence. What explains this lack of awareness and evidence is taken to be the fact there is no related way the world visually seems to be to him. See Block (1995) and Smithies (2011).

2 I take these assumptions to be shared by a variety of representationalist theories among these are: Byrne (2009), Dretske (1995), McDowell (1996), Peacocke (1983), Searle (1983), Siegel (2010) and Tye (2000).

${ }^{3}$ Notice this claim is weaker than the intentionalist claim that phenomenology supervenes on content. All the above requires is that part of what explains how the world seems to me is how it is represented as being.
} 
The representational theory thus motivates its attribution of content to experience, because this allows for an explanation of how awareness is linked to evidence, and the world seeming a certain way to one. The representational theory of perception has faced serious opposition, especially in recent years. ${ }^{4}$ However, for present purposes, I will assume that it is correct and rather deal with the internal issue of how we should logically account for the content we attribute to experience.

A prevalent intuition has it that when I perceive I am aware of the specific particulars that figure in my environment. It doesn't seem to me as if some tree is blossoming, or as if a tree is blossoming, rather it seems to me as if a specific tree is blossoming. ${ }^{5}$ Likewise, many think that perception provides experiential evidence for singular judgements, that is, judgements whose truth or falsity inherently turns on how things are with a specific particular. ${ }^{6}$ It is difficult to see how my perceptual state could support my judgement that a specific tree is blossoming, if all I am aware of is that some tree, or a tree, is blossoming. To satisfy these intuitions, it has been suggested that our perceptual states have singular content. ${ }^{7}$ When I am perceptually aware that a specific tree is blossoming, it is because my perception has content roughly on the form of 'that tree is blossoming'. Hence:

Singular Content Intuition: Perceptual experiential states have singular content.

Another persistent philosophical intuition is that things can experientially seem the same to me irrespectively of whether I am in a perceptual state or in a subjectively indistinguishable hallucinatory state. Likewise, it has been argued that perceptions and indistinguishable hallucinations provide similar experiential evidence. These intuitions have given rise to the theory that perceptions and subjectively indistinguishable hallucination share experiential content. ${ }^{8}$ Given the representationalist thinks content explains how the world seems and what evidence an experience provides, such shared content would explain why perceptions and indistinguishable hallucinations provide similar evidence and why the world seems the same to one such cases. Hence:

Same Content Intuition: Perceptual experiential states and subjectively indistinguishable hallucinations share the same content.

\section{The predicament}

A central problem for a representational theory of perception is that the Singular Content Intuition and the Same Content Intuition seem to be in conflict. If my perceptual state has singular content, then there must be a specific object that the

\footnotetext{
4 See especially Campbell (2002), Brewer (2006), and Travis (2004).

5 See McDowell (1986), Brewer (1999), Campbell (2002), Fish (2009), Schellenberg (2011), Tye (2007) and Travis (Forthcoming).

6 See Brewer (1999) and (2011), Campbell (2002), Evans (1982) and McDowell (1996).

7 See Brewer (1999), McDowell (1996) and Tye (2007).

${ }^{8}$ See Byrne (2001), McGinn (1982), Searle (1983) and Siegel (2010).
} 
truth or falsity of my experiential representation turns upon. We can characterize a simple case of singular content as having a logical structure on the form: ' $\alpha$ is F'; where it is inherent to that logical structure that the place of ' $\alpha$ ' must be filled with a specific particular upon which the truth and falsity of the content turns. In an unproblematic case of perception, the space of ' $\alpha$ ' will be filled with the object that I am visually related to, say, the specific blossoming tree in front of me.

The problem is that in the case of hallucinations there does not seem to be any way of determining a particular tree as the one upon which the truth or falsity of my experiential content turns. Why should any tree, rather than any other, be relevant to the truth of the content of a hallucination? Consequently, it has been argued that hallucinations cannot possess singular contents. Rather, they must have general contents, which specify that some general state of affairs occur, but are neutral as to what specific particulars are involved in its occurrence. ${ }^{9}$ Thus, the content of hallucinations is often characterized on a form such as: 'some $\mathrm{X}$ is F', or 'an $\mathrm{X}$ is F'. Where, in our case, any tree can make the representation true as long as it is blossoming. ${ }^{10}$

However, if hallucinations cannot have singular content, and perceptions and subjectively indistinguishable hallucinations share the same content, then perceptions cannot have singular content either. ${ }^{11}$ Hence, it seems that we must either give up the Same Content Intuition or the Singular Content Intuition. A central debate in recent philosophy of perception aims at determining which of these intuitions we should give up. However, in a series of recent articles Susanne Schellenberg (2011, 2013a, b, 2016a) has argued that, if we adopt a proper account of experiential content, we can both conserve the Singular Content Intuition and the Same Content Intuition.

\section{Schellenberg's solution}

Schellenberg (2011: 742, 2013a: 303, 2013b: 29-31) employs a Fregean account of content, where such contents are individuated, not only by their reference, but also by the Sense, or mode of presentation, with which these referents are given. Her idea is to argue that the contents of perceptual states and indistinguishable hallucinations share the mode of presentation with which their referents are given. This is meant to accommodate the Same Content Intuition. She aims to satisfy the Singular Content Intuition by claiming that the logical structure of the contents of both perception and hallucination is singular. Yet, in the hallucinatory case no referent is singled out. The ' $\alpha$ ' space in the singular logical structure is left empty.

\footnotetext{
${ }^{9}$ See Byrne (2001), Crane (2003), and Searle (1983).

${ }^{10}$ Various further properties have been suggested as inherent in the general content of experiences, such as the requirement that the blossoming tree be the one causing this experience [see Searle (1983) for an initial presentation]. We can ignore these further complications as our concern is solely with the logical difference between singular and general representations.

${ }^{11}$ That is on the assumption that subjectively indistinguishable hallucinations are at least metaphysically possible.
} 
Hallucinations have what she calls 'gappy contents' (2013a: 304, 2013b: 31, 2016a: 879).

Schellenberg (2011: 742, 2013a: 303, 2013b: 29-31) schematically presents her idea on the following form: An experience as of a white cup has a mode of presentation of particular-whiteness and a mode of presentation of that-particularcup; call these 'MOP-White' and 'MOP-Cup'. She characterizes the content of indistinguishable hallucinations and perceptions of numerically different but indistinguishable objects as follows:

\section{Perception 1: MOP-White $(\gamma)$; MOP-Cup $(\alpha)$}

Perception 2: MOP-White ( $\delta)$; MOP-Cup $(\beta)$

Hallucination: MOP-White (); MOP-Cup ()

Schellenberg's idea is that all three cases share a single potentially gappy Fregean content-schema, or mode of presentation. In the two perceptual cases, the contentschema has its gap filled with specific particulars, such that they amount to different ordinary singular contents. In the hallucinatory case, the schema remains gappy.

Schellenberg (2011, 2013a, 2013b, 2016a) takes the main benefit of her theory to be its ability to satisfy both the Singular and the Same Content intuitions. She wants to account for the fact that the world can seem the same to me irrespectively of whether I perceive or undergo an indistinguishable hallucination, by arguing that how the world seems to me is determined by the potentially gappy singular contentschema that is shared by these states. Likewise, she wants to argue that the shared experiential evidence I acquire in both cases has a common basis in how the world seems to me, and thus in the shared content-schema possessed by both the perceptual state and the hallucination. Schellenberg (2016a: 880) calls this shared evidence for 'phenomenal evidence'. This explanation is meant to satisfy the Same Content Intuition. To satisfy the Singular Content Intuition, she argues that my perceptual awareness of specific particulars is grounded in the singular content of the filled singular content-schema that my perceptual state has. Similarly, the experiential evidence that only the perception provides for singular judgements is based upon the relations between the filled singular content-schema of my perception and the relevant singular judgement. Schellenberg (2016a: 880) calls this latter type of evidence for 'factive evidence'.

There is a potential danger in such a divide and conquer strategy, which is that we have been given two explanatory grounds for what we initially took to have a single explanation. We sought a single representational account of the nature of seemings, perceptual awareness, and experiential evidence. However, that account was stymied once we realized that in order to satisfy both intuitions we had to attribute content with contrary logical forms to our experiences. Schellenberg now tells us that the mistake lay in thinking that all the explanatory work was to be done by the attribution of content to experience. Part of the explanatory work rests on the attribution of, not content, but content-schemas to experience. Her suggestion is to make the following revision to the first two representational commitments set out above: 
$1 *$. How the world seems to me is a matter of what content-schema my experience has.

$2 *$. When the world seems to me a certain way, I have experiential phenomenal evidence for judgements whose content is suitably related to the content-schema of the experience that explains how the world seems to me.

In the next section of the paper, I will discuss how Schellenberg can enable contentschemas to do the work that the ordinary representationalist took contents to do. In the final section of the paper, I will argue that once we see how Schellenberg is forced to solve this issue, she has no way to provide a substantial explanatory connection between what I am perceptually aware of and how the world seems to me. Thus, Schellenberg can provide no analogue explanation to that given by the third representationalist commitment which claimed that:

3. To be perceptually aware of the world is to be aware that the world is as it seems to me; that is, I am aware that the world is as my experience represents it as being.

However, we cannot accept a theory of perceptual awareness that severs all explanatory connections between what I am aware of and how the world seems to me. Hence, I will ultimately argue that Schellenberg's theory fails.

\section{How can gappy content-schemas do the work of contents?}

There is a rather simple argument that leads from the notion that things seem a certain way to the idea of truth or accuracy conditions, and thus to contents. ${ }^{12}$ Schellenberg (2011: 719) acknowledges this as part of what she calls 'the master argument' for experiential content. The argument starts from a rather intuitive premise: when the world seems a certain way to a subject, then the world either is as it seems to her or it isn't. ${ }^{13}$ This feature of what it is to have the world seem a certain way is explained in terms of the truth-conditions of the experiential content on a representational theory of experience. As Schellenberg writes (2011:726):

The way the world seems to a subject determines the way the world would have to be for the content of her experience to be accurate. The world is either the way it seems to her or it is different from the way it seems to her.

It is too weak an interpretation to read the quote above as merely instating a material implication between the satisfaction of the truth-conditions of certain experiential content and the fact that the world is as it seems to one. If that were the case, the attribution of content would play no explanatory role in accounting for how the

\footnotetext{
${ }^{12}$ For simplicities sake, I use 'truth-conditions' to refer to the conditions when things are as represented by any form of content, be that judgmental, linguistic or perceptual. Nothing rides on this choice, I might as well have used the notion of 'accuracy conditions' for experiential content.

13 See Schellenberg (2011) and Byrne (2009) for responses to the Travis (2004) and Brewer (2006) objections to this view. I am not committed to the adequacy of these responses; my point is solely that the representationalist accepts this premise.
} 
world seems to one. The representationalist motivates the attribution of content to experience partly because it is meant to figure in the explanation of how the world seems when it seems a certain way to a subject. Hence, the following claim is central to an ordinary representationalist theory:

A. There is an explanatory connection between the conditions under which the world is at is seems to a subject and the truth-conditions of the content of her experience. $^{14}$

We get a similar conclusion once we look at the representationalist account of our experiential evidence. Non-representational accounts of experience typically argue that an experience justifies a certain judgement because the experience counts as a case of conscious awareness of the very truth-makers of the judgement. ${ }^{15}$ In contrast, the representationalist argues that it is relations between the truthconditions of our experiences and the truth-conditions of our judgements that settle what judgements an experience provides experiential evidence for. ${ }^{16}$ Thus, the representationalist accepts the following:

B. There is an explanatory connection between the judgements a subject acquires experiential evidence for and the truth-conditions of the content of her experience.

Schellenberg suggests that we can explain both how the world seems to us and what phenomenal evidence we possess in terms of the potentially gappy singular contentschema that is shared between hallucinations and perceptual states. The problem is that, whereas contents have truth-conditions, potentially gappy content-schemas do not.

Consider again a simple singular representation with the logical structure: ' $\alpha$ is $F$ '. It is part of the nature of a singular representation that its truth and falsity turns on how things are with a specific particular. ${ }^{17}$ A general content, such as that of the statements 'a cup is white' or 'some cup is white', can be made true by any white cup. However, for any singular content there is a specific cup whose properties determine the truth of the falsity of the content. What characterizes singular contentschemas, as opposed to singular contents themselves, is precisely that the instantiation of the schema alone is neutral on which specific particular it is that fills the singular place in the logical structure. In fact, the instantiation of such content-schemas is, according to Schellenberg (2013b: 30-31), neutral as to whether there is even a specific particular filling that place, or whether the logical structure is left with a gap. This entails that such content-schemas are, on their own, non-truthevaluable. The point isn't that they are uniformly false, nor that they can in isolation be made true by any particular, just like a general content. They retain their singular

\footnotetext{
14 Schellenberg (2013b: 294) acknowledges this when she writes: "the accuracy conditions [of the sensory character of experience] are read of the content of experience".

15 See Brewer (2011), Johnston (2006), Kalderon (2011), and Travis (Forthcoming).

16 See among others: Peacocke (1983), McDowell (1996) and Siegel and Silins (2013).

17 See Evans (1982) and McDowell (1984).
} 
structure (2013b: 31, 2016a: 879). Hence, they aren't truth-evaluable at all. There are no conditions that counts as those under which a content-schema is true or false. Just like nothing is represented by the claims 'Tod' or 'is crunchy', there is nothing represented by a content-schema alone.

Oddly enough, Schellenberg (2013b: 30-31) describes even non-truth evaluable hallucinatory states, where the content-schema contains a gap, as states with content, as when she writes:

Since there is no failure on the level of employing the capacity, there is no reason to think that the mental state of hallucination does not have a token content ... Employing perceptual capacities gives sufficient structure for the relevant experience to have a token content.

Thus, when she (2013b: 32) says a hallucinatory state purports to have singular content, she would still claim that it does in fact have content, due to the state being occasioned by the exercise of perceptual discriminatory capacities. Only this content is neither singular, nor general, it is gappy. This usage of the notion of 'content' clearly puts her apart from the ordinary Fregean ancestry of the representationalist, where the notion of content is reserved for states that present a way the world can be or fail to be. To Frege, my use of the concept 'Tod' in isolation would fail to have content, precisely due to is lack of truth-evaluability. This is the point of his Context Principle that states that only in the context of a complete proposition does a concept have meaning (Frege 1884: 73). Even though multiple conceptual capacities are exercised in providing the concept-schema of a hallucination, they still lack truth-evaluability, and that is the crucial point which means that to Frege they fail to be contents. This difference in terminology is important in evaluating Schellenberg's theory as an account of experiential content. Schellenberg can remain adamant that "content", on her reading, plays an important role in explaining how things seems to us and what evidence and awareness we possess. ${ }^{18}$ However, the traditional representationalist explanation included contents precisely because their possession of truth-conditions enabled them to explain both justificatory relations, and how the world would have to be to be as it seemed to us. Schellenberg must explain how the mere fact that a state instantiates a non-truth evaluable content-schema can play the same explanatory role.

Importantly, Schellenberg cannot simply skip the role of truth-evaluability and give her account directly in terms of justificatory relations between our exercise of capacities and the judgements we form on that basis. If she did so, she would have adopted a brute reliabilist account of perceptual evidence, where the mere fact that we judge in response to the exercise of capacities with a reliable or constitutive connection to a type of worldly states suffice to justify our judgement that such a

\footnotetext{
${ }^{18}$ Unless explicitly stated I retain the traditional terminology and solely use 'content' to refer to representations that are truth-evaluable. Schellenberg could follow the non-Fregean tradition of attributing 'content' to even non-truth-evaluable usages of syntactic tokens. However, this is a mere terminological issue, as the main issue is how she provides an alternative to the traditional representational explanatory connection between the truth-conditions of experiential content and how the world seems.
} 
state occurs. The representationalist introduces the idea that our perceptual states represent the world to the subject precisely because he wants to avoid such brute reliabilism. He respects the unique subjective aspect of experiential evidence, which is that our perceptual judgements aren't based blindly on the exercise of capacities, but are rather based on our subjective appreciation of how the world seems to us and how we are aware of it as being. The core of the representationalist theory is precisely to claim that truth-evaluable contents are needed in order to explain what we are aware of in perception and how the world must be in order for it to be as it seems to us. Schellenberg needs some alternative way of accounting for what it is for the world to be as it seems, when she takes the primary explanatory factor to be the mere fact that we are in a state that has a non-truth-evaluable content-schema. For such a schema alone does not specify any way the world can be of fail to be.

Schellenberg is sensitive to this explanatory requirement and her answer to it has two elements. First of all, she argues (2013b: 17-18, 2016a: 2) that the discriminatory selective perceptual capacities that we exercise in both perception and hallucination are metaphysically individuated in terms of how they function in the successful perceptual cases. In other words, we are in an experiential state that instantiates a certain content-schema, because we are exercising capacities that function to single out specific particulars of a certain type. Hence, we can only understand what it is for a state to have a content-schema in terms of what it is to successfully have a certain type of content. Secondly, she argues (2013a: 299, 2013b: 31) that even though hallucinatory states fail to possess truth-evaluable contents, they still purport to possess such contents. We can understand these two features in light of each other. Our perceptual system exercises certain capacities that function to single out particulars of a certain type. When we exercise these capacities, they purport to have fulfilled that function, irrespectively of whether they have actually succeeded in doing so. Hence, our perceptual capacities function to bring about experiential states with singular contents of a certain type, say, one of those singular contents using the modes of presentation MOP-Cup and MOP-White. Whenever we exercise these capacities, our perceptual system purports to be in a state with a singular content that represents a specific cup as being white.

At an initial glance, Schellenberg's elaborated account has brought us no closer to a solution. If content initially explained how the world seems to me and what experiential evidence I get, how can the fact that a state merely purports to have a certain type of content do the same explanatory work. After all, that fact that I purport to build a bridge cannot enable river crossings in the same way as a successfully built bridge can. To understand what motivates Schellenberg's approach, we must look to an analogy between the functioning of content in testimony and its assumed role in perception. Schellenberg (2013b: 37-38, 2016a: 883 ) explicitly aligns her account of the singular content of perception, and the explanatory role of content-schemas, with how we understand the role of demonstrative contents in testimony. By looking at this analogy in closer detail, we can unearth the reasons why Schellenberg thinks she can attribute the explanatory role that is ordinarily attributed to truth-evaluable contents to non-truthevaluable content-schemas. 
When I hear a demonstrative statement with a singular content that I understand, I become aware of how things stand with its specific referent and have evidence for suitably related judgements. If Tod points and says to me 'that horse is eating an apple', this will make me aware of how things stand with that specific horse. On a common account of what is going on, my capacity to acquire awareness and evidence from hearing demonstrative statements come from the exercise of two separable capacities. ${ }^{19}$ On the one hand, there is my appreciation of the function of the words Tod uses. I know that his demonstrative 'that horse' is meant to pick out a perceivable horse. On the other hand, there is my perceptual awareness of the horse that he points to. When these are exercised in combination, I understand the content of Tod's demonstrative statement and, thereby, get testimonial awareness and evidence.

Importantly, in the absence of my perception of the horse, I wouldn't understand Tod's demonstrative statement, as I wouldn't grasp what specific horse the statement referred to. However, I could still acquire some level of awareness of the world and some form of evidence, simply from my understanding of the function of the words Tod used. Imagine that Tod is standing at a cross-road, pointing down a road that is blocked from my view. Now I won't understand the content of Tod's demonstrative, as I don't know what horse he refers to; or if he even refers, he may be hallucinating for all I know. However, I still acquire awareness that there is some specific horse that Tod takes to be eating an apple. I know this simply by understanding the function of the words involved in Tod's demonstrative statement, even though I cannot understand its content. Schellenberg's (2016a: 883) idea is that the role of content-schemas in experience function analogously to the general role of Tod's words in the account of testimony involving demonstrative statements.

The idea is the following: When I am in any experiential state I exercise discriminatory selective perceptual capacities that function to pick out specific particulars of a certain type. These types are settled by the mode of presentation involved in the gappy-content schema, such as MOP-Cup. This content-schema functions analogously to Tod's word 'that horse', which is meant to single out a specific horse. My mere awareness of Tod's word use provides me with evidence for the general judgement that there is some specific horse that is eating an apple. I may not know which horse, but I have evidence that there is some such horse eating an apple. This is the case even if Tod in fact fails to pick out any specific horse with his demonstrative. I will still have the same evidence, though I will be misled. Similarly, the mere fact that I exercise my discriminatory selective capacities which functions to pick out cups and whiteness, is meant to provide me with evidence that there is some specific cup that is white; though I won't know which one simply based on the fact that I exercise these capacities. This conclusion is precisely what Schellenberg (2016a: 883) aims at when she claims that the phenomenal evidence I get from being in experiential states that instantiate a certain content-schema is solely evidence for general statements. Notice that Tod's demonstrative statement retains its singular logical form, even when it solely provides me with evidence for

${ }^{19}$ See Kaplan (1989) and Perry (1977). 
general judgements due to my failure to perceive the relevant horse, and thus, grasp its content. Likewise, Schellenberg argues that hallucinations retain their singular logical structure even when we solely acquire phenomenal evidence for general judgements in virtue of the instantiation of a certain content-schema.

At this stage, we can appreciate the rough structure of Schellenberg's solution, however, there is still a serious explanatory gap to be filled. In the parallel testimonial case, we are left with an initial conundrum. When I successfully understand a demonstrative, the idea is that we can explain both my awareness and the evidence I get in terms of my grasp of the content of the demonstrative. However, we have now acknowledged that I can also get awareness and evidence, albeit only of a general condition, in cases where I clearly fail to grasp the singular content of the demonstrative. What explains what I am aware of and what evidence I get in these cases? The natural solution is to argue that even while I do not grasp the content of the demonstrative, there is another related content that I grasp. I grasp the content of the presuppositional commitments that Tod incur by using those words. It is a presupposition of the rational use of the demonstrative statement 'that horse is eating an apple', that there is some specific horse that is eating an apple which one's demonstrative statement manages to single out in the current environment. The reason that I acquire both awareness and evidence on the basis of hearing Tod's demonstrative statement, even when I cannot see the horse he refers to, is that I appreciate what Tod's presuppositional commitments are. We can in turn explain both the nature of what I am aware of, and the nature of the evidence I acquire, in terms of the fully truth-evaluable contents of those presuppositions. The presupposition of Tod's use of the demonstrative statement have general contents roughly on the form: There is some specific horse that I manage to single out and that horse is eating an apple. What I can become aware of merely upon hearing Tod's words is precisely that the world is as that presuppositional content represents it to be. Likewise, the judgements I acquire evidence for can be determined in terms of relations to the truth-conditions of the content of the presupposition. Hence, when Tod uses his demonstrative statement, he not merely explicitly represents the world as being as the content of that demonstrative statement represents it, he also implicitly represents it as being as his presuppositional commitments represent it as being. And I can grasp the general content of the latter, even when I fail to grasp the singular content of the former. Hence, in the testimonial case, we retain the central representational idea that all testimonial awareness and evidence is explained in terms of grasp of truth-evaluable contents.

In Schellenberg's perceptual story, we are likewise owed an explanation. What on her account explains how the world seems to me and what judgements I get phenomenal evidence for? Simply stating that this is due to the potentially gappy content-schema shared by hallucinations and perception is no explanation. For it was precisely the truth-evaluability of contents that enabled the representationalist explanation, and content-schemas aren't truth-evaluable. So, what, on Schellenberg's account, is meant to fill the explanatory role that is filled by our grasp of the truth-evaluable contents of the presuppositional commitments in the testimonial case? 
The most tempting solution is to maintain a strong analogy with the testimonial case. Schellenberg can argue that by exercising discriminatory selective perceptual capacities my visual system incurs something analogous to presuppositional commitments, and that such exercises mean that the world seems to me as if these general conditions are fulfilled. For example, on Schellenberg's favorite white cup example, it would be a presupposition of the proper function of my perceptual system's exercise of those discriminatory capacities that there is a specific white cup in my environment that my exercise of those capacities manages to single out. On this reading, Schellenberg's solution would differ from the ordinary representationalist by arguing that my phenomenal evidence, and how the world seems to me, isn't explained in terms of the content of my experiential state. Rather, this is explained in terms of the content of the "presuppositional commitments" that my visual system incurs by exercising the perceptual capacities that award a certain content-schema to my experience. However, she would retain the central representational idea that we explain what it is for the world to seem to me a certain way in terms of a certain content. On this view, when the world seems a certain way to me, it seems as if the preconditions for the successful exercise of my perceptual capacities are fulfilled. Another formulation of this general approach would argue on the basis of perceptual phenomenology that every experience seems to me to have a singular content, or in more basic terms, seems to be an experience of a particular of a certain type. ${ }^{20}$ However, that an experience has some singular content, or is of some particular of a certain type, is a general condition, which can be accounted for in terms of the truth-conditions of some general content. Things phenomenally seem as if there is some specific white cup that my experience is of. What separates the two suggested formulations of the same idea is what is represented in the general contents that explains how the world seems to one. Either this content merely mentions non-psychological worldly conditions such that the world seems as if some white cup is present (hence, it seems as if the success conditions for the exercise of the perceptual capacities is fulfilled). Alternatively, the content can mention psychological conditions, such that it seems as if I experience some specific white cup (hence, it seems as if the perceptual capacities have been successfully exercised). ${ }^{21}$ Either way, we explain how the instantiation of mere content-schemas can fulfill the explanatory role of truth-evaluable contents by means of the representation of some suitably related fully truth-evaluable general contents.

I think Schellenberg is forced to adopt some version of an explanation that centrally involves general contents as the explanans. But, as I will later argue that this leads her into trouble, I will briefly explain why alternative explanatory routes won't work. Recall, the central challenge is to explain how the world seems to me and what phenomenal evidence I get, when this cannot be accounted in terms of the truth-evaluable content of my experience. There is clearly no singular content in terms which Schellenberg can explain this, given her commitment to providing the

\footnotetext{
${ }^{20}$ I owe this second formulation of the view to very helpful comments from Keith Wilson.

${ }^{21}$ Notice this later view rejects full transparency of experience.
} 
same explanation in both perceptual and hallucinatory cases. And the instantiation of gappy-content schemas doesn't provide an explanation on its own, as they lack truth-conditions. This means the only alternatives for Schellenberg is to either adopt a story like the above, where a general content in some way explains how the worlds seems and what evidence I get, or to outright deny that this explanation has anything to do with truth-evaluable contents. However, the latter strategy won't work for Schellenberg. ${ }^{22}$

Schellenberg (2013b: 17-18, 2016a: 887) is keen to impress on us that the perceptual capacities that explain both the possession of content-schemas and how the world seems to us are metaphysically individuated in terms of their function in the successful perceptual case. Yet, how does that explain how the world seems and what experiential evidence the subject possesses? Many capacities are individuated in terms of their successful functioning, yet this doesn't mean that we get experiential evidence just by exercising them. Imagine that I have a capacity for performing a series of rhythmic movements that can only be individuated in terms of its function of making me swim when immersed in water. If I involuntarily exercise this capacity that alone surely won't provide me with experiential evidence that there is water present or swimming going on, nor make things seem that way to me. Schellenberg needs to explain what makes it the case that our mere exercise of perceptual capacities has this consequence. ${ }^{23}$ Simply saying that is because these capacities are perceptual capacities, or explaining it by saying that this is because they bring about states with content-schemas, is to provide no answer at all. We want an explanation of what makes it the case that the exercise of perceptual capacities makes the world seem a certain way to us and provide us with certain experiential evidence, when the exercise of other capacities doesn't. The direct realist explains this by saying that the exercise of perceptual capacities enables an explanatorily primitive conscious relation to the external world, and the state of the world we are conscious of then itself explains how things seem to us and what evidence we get. ${ }^{24}$ The representationalist explains this by saying that the exercise of perceptual capacities brings about representational states with content, and the truth-conditions of this content then explains how the world seems to us and what evidence we get. $^{25}$

Schellenberg cannot simply state that the exercise of perceptual capacities brings about states with content-schemas as her parallel to the representational explanation, for content-schemas lack the truth-conditions necessary to explain how the worlds seems to us and what evidence we get. She needs to explain how the exercise of our perceptual capacities relate the subject to certain worldly conditions. The fact that these capacities are individuated partly in terms of those conditions doesn't in any way explain how those conditions come to determine how the world seems to the

\footnotetext{
${ }^{22}$ It can work if one adopts a direct realist approach to perception, but for the purpose of this paper I work on the assumption of the truth of the representational theory of perception.

23 See Neta (2016: 912) and McGrath (2016: 903) for similar lines of objection.

24 See Campbell (2002) and Brewer (2011).

25 See for example: Peacocke (1983), Searle (1983), McDowell (1996), Siegel (2010), Siegel and Silins (2013), Tye (2000).
} 
subject or what evidence she gets. So far, the only options we know of are to argue that these conditions are represented to the subject as obtaining or directly perceived by the subject. Stating that a capacity has certain metaphysical individuation conditions may tell us about certain reliable or historical connections that must exist between the possession and exercise of that capacity and the worldly conditions under which it fulfill its function. Moreover, this story may prove a valuable addition to the ordinary representational story as to why experiences with content justify as opposed to, say, hopes with content. ${ }^{26}$ But the metaphysical individuating fact alone doesn't suffice to explain how it comes to be that the world seems a certain way to a subject when that capacity is exercised. At best, it can ensure that any subject who exercises those capacities will have a brute reliabilist or functionalist form of evidence, but that evidence would be possessed independently of how the world seemed to the subject, as long as his judgements were suitably connected to the conditions under which his capacity functioned.

Schellenberg can surely explain what general judgements I get evidence for by pointing to the general conditions under which my perceptual capacities have fulfilled their function. However, if this is to remain a representational account of experiential evidence then what I get evidence for judging must be connected to how the world seems to me. And if the world seems to me a certain way then that is a way the world can either be or fail to be. As long as she rejects any direct realist account, Schellenberg must explain how the world seems to me in terms of some general contents. If she attempts to explain how the world seems to me directly in terms of content-schemas, then she rejects that the world could be as it seems to me, for content-schemas, gappy or not, aren't truth-evaluable. However, Schellenberg (2011: 725-726) explicitly acknowledges that it is a requirement for an adequate account of seemings that it accepts that for it to seem that the world is a certain way is for there be a way the world can be such that it is as it seems to one. Hence, the only reasonable option is for Schellenberg to acknowledge that how the world seems to us is as if certain general conditions obtain.

\section{From general seemings to singular awareness}

We have reached the interim conclusion that Schellenberg can satisfy the Same Content Intuition. To do so, she has to explain how the world seems to a subject in terms the representation of a general content. The final challenge facing her theory is to combine this explanation with a successful account of how we can be perceptually aware of specific particulars and acquire factive experiential evidence for singular propositions. She needs to explain these latter points if she is to maintain the main motivation for her theory, which is that it can satisfy the both the Same Content intuition and the Singular Content Intuition.

Intuitively, there is a significant connection between having perceptual awareness of the world and having it seems to one as if the world is a certain way. However, it

26 This is one explanatory role Schellenberg (2016b: 931-932) attributes to the capacity story. 
is rather unclear how Schellenberg envisages this connection. ${ }^{27}$ She explicitly acknowledges that:

It is not contentious that if one is perceptually related to the world, then one will be aware of the world. Moreover, it is not contentious that if one is aware of the world, then the world will seem a certain way to one... (2011:722).

However, we are surely looking for a deeper connection between perceptual awareness and phenomenology than a mere material implication. Rather, we are looking for an explanatory connection between instances of perceptual awareness and instances where the world seems a certain way to a subject. There are many ways in which one can become aware of something, being told, remembering, or perceiving. Intuitively, it seems that what enables perceptual awareness is the fact that one is in a state with perceptual phenomenology, just like the fact that I hear someone's words enables awareness through testimony. I want to suggest that any adequate theory of perception must operate under the following assumption.

C. How the world seems to me must at least partly explain what I am perceptually aware of.

Moreover, I want to argue that Schellenberg's theory cannot meet this requirement. But first I want to point out that the ordinary representationalist and the direct realist have easy explanations that satisfy this requirement. For the direct realist, how the world seems to me is determined by the properties of the specific mind-independent objects that I stand in a relation of conscious awareness to, and to stand in that relation of conscious awareness simply is to have things seem to me to be a certain way with those specific objects. ${ }^{28}$ The relation of perceptual awareness simply is to have things seems to me as I am perceptually aware of them being. On the ordinary representationalist account, the world seems to me as it would be if a certain content were true, and when I perceive I am precisely aware that things are as represented to be by that content. It is because things seem as if $\mathrm{P}$ to me, that I am aware, in the perceptual case, that they are indeed P. For those who favour the Singular Content Intuition, the contents that explain how things seems are singular, and I am perceptually aware of how things are with specific particulars. For those who favour the Same Content Intuition, the contents that explain how things seems are general, and I am at best perceptually aware that general conditions obtain. Schellenberg's challenge is to explain how we can retain an explanatory role for how things seem to one in explaining perceptual awareness, when how things seem to one is explained in terms of general contents, whereas our perceptual awareness is an awareness of how things are with specific particulars. When it simply seems to me as if some specific cup is white, how can this be of help in making me aware that the specific cup $\alpha$ is white? After all, the former would be the case even if it had been the white cup $\beta$ that I had been perceptually related to.

\footnotetext{
27 I want to thank an anonymous referee for motivating me to elaborate on my own and Schellenberg's commitments in this regard.

28 See Brewer (2011), Fish (2009) and Martin (2002).
} 
There are three forms that Schellenberg's response might take: She might outright reject the requirement that we explain perceptual awareness partly in terms of how things seem to us. She might argue that we get awareness of how things are with specific particulars because of some further feature internal to the subject's point of view, which in combination with how things seem to us, enable perceptual awareness of specific particulars. Finally, she might argue that it is further features external to the subject's point of view, which explain how we get awareness of specific particulars when the world seems to us as if a general condition obtains. In this final section of the paper, I will argue that none of these answers will suffice.

Schellenberg's (2011: 729) view is that we aren't aware of the world by being aware of contents; rather we are aware of the world by being in states with content. On this basis, one might take Schellenberg to simply claim that what explains my perceptual awareness is just that I am in an experiential state that has full truthevaluable singular content. ${ }^{29}$ It is a further explanatorily independent feature of how of our perceptual system is rigged up that the world seems to us a certain way when this occurs. However, this further feature is no part of the explanation of why we have the perceptual awareness we do. ${ }^{30}$ All this account claims is that there is a common explanation of what content our perceptual state has and how the world seems to us. Both are explained in terms of the exercise of the same discriminatory selective capacities. Schellenberg (2016a: 881) seems to hold this view as she accounts for what unifies our phenomenal and factive evidence the following way: "Phenomenal evidence and factive evidence are epistemically united in so far as both are provided by mental states that are constituted by employing perceptual capacities".

The problem with this account is that it fails to explain why perceptual awareness provides the subject with evidence that has any form of special epistemic significance; rather than with mere externalist justification in some sense. ${ }^{31}$ Recall, part of the motivation for ascribing content to experience is precisely to enable an epistemic view of perceptual justification that differs from brute reliabilism. Yet, if it is merely epiphenomenal in relation to my perceptual awareness that the world seems a certain way to me; then how do we justify the intuition that perceptual awareness inherently provides information about the world that has a special significance to the conscious reasoning of a subject. Presumably, it is the fact that experiences are phenomenologically present that explains why perceptual states have special significance for the conscious reasoning of the subject; as opposed to

\footnotetext{
29 There might be further requirements. I may I have to be in a cognitive state with content that is poised [see Tye (1995)], or is broadcasting, or some such notion. (Thanks to an anonymous referee for pointing this out).

30 Thus, Tye's (1995) PANIC theory doesn't provide an example of this line response. On his account, how the world seems to me explains what I am perceptually aware of in successful cases of perception, as being in a state where the world seems to me a certain way is simply identical to having a state of perceptual awareness; that is a state which is poised for a special epistemic role.

31 By 'special' I mean the type of significance that externalist justification typically fails to possess. Such evidence has been called: 'internalist', 'accessible', 'consciously present', or simply named 'justification' as opposed to 'warrant'. The key difference is between this and the typical notion of externalist evidence which a subject isn't rationally required to consider in his reasoning.
} 
the significance that various other content bearing cognitive states may have. Yet, if how the world seems to me, the phenomenology of experience, plays no explanatory role in the account of what I am aware off, then it is hard to see how the singular content of my state of perceptual awareness could acquire the same epistemic significance to consciousness, that the general content related to the phenomenologically present state of seeming has. All we are told by Schellenberg is that the fact that the world seems to me as if a general content is true is caused by the same event as the fact that I am perceptually aware that a singular content is true. The phenomenal presence of the general content can explain why that content plays a special role as evidence, but we have been given no account of why the same special status should be applied to the evidence provided by the singular content of our perceptual awareness. Schellenberg could, of course, use a weakened notion of perceptual awareness, where such awareness doesn't provide evidence with any special significance to consciousness. However, in that case she would have failed to satisfy the singular content intuition; for that intuition is in part motivated by the idea that we have evidence which justifies singular judgements which possesses this special epistemic significance. ${ }^{32}$ The typical explanation within philosophy of perception is that the phenomenology of experience, how the world seems to me, is what accounts for the special epistemic status of experiential and perceptual evidence. Hence, any adequate account of perceptual awareness must at least partly explain perceptual awareness in terms of how the world seems to me. Otherwise, it cannot exploit the phenomenology of experience as its explanation of the special epistemic significance of perceptual awareness. Hence, unless one can explain why the contents of perceptual awareness have special epistemic significance to the conscious rational reasoning of a subject without alluding to the fact that experiences have phenomenal presence, then one must accept condition $\mathrm{C}$ as stated above. $^{33}$

Schellenberg second option was to argue that how the world seems to us must be combined with a further feature of our subjective point of view, and in unison these two elements explain how we can be aware of specific particulars, even though the world merely seems as if a general condition obtains. This view is tempting because it retains the strong analogy with how our understanding of demonstrative statements is explained. In virtue of my understanding of the role of the words Tod use, I can appreciate the presuppositional commitments he incurs and get awareness and evidence that is explained in terms of general contents. However, once my linguistic understanding is coupled with my perceptual awareness of the horse that Tod is pointing to, not only do I manage to grasp the general content of his presuppositional commitments, I also manage to grasp the singular content of his demonstrative statement itself. Hence, the addition of my capacity for perceptual awareness of mind-independent particulars and its successful exercise, has granted me awareness of singular contents by cooperating with my linguistic understanding,

\footnotetext{
32 Again, see Brewer (1999) and (2011), Campbell (2002), Evans (1982), McDowell (1996).

33 I owe great thank to the helpful comments of an anonymous reviewer which forced me to elaborate on the importance of this explanatory relation.
} 
which on its own could only grant me awareness of general contents. Importantly, my perceptual awareness of the horse wouldn't by itself provide me with the evidence I acquire when the two capacities are cooperating. I may not be able to see whether the horse is eating from my vantage point. What is crucial is that my capacity for linguistic understanding retains a vital role in explaining my grasp of the singular content of the demonstrative statement.

Unfortunately, a story along these lines won't work in the perceptual case. The problem is, that the second capacity that is introduced to explain our grasp of the singular content of the demonstrative statement, is our perceptual awareness of the horse that figures as the referent. However, such perceptual awareness of mindindependent particulars is precisely what our theory of perception is meant to explain. Hence, we cannot introduce such awareness as what is added to my being in a state where the world seems a certain way to me, such that I acquire perceptual awareness of specific mind-independent particulars. The story of how we grasp demonstratives works precisely because there exists a more basic way of being aware of particulars than hearing about them through testimony, and we can explain our grasp of testimonial demonstrative singular content partly in terms of our possession of that capacity. However, there is no more basic capacity for awareness of mind-independent empirical particulars than perception. Hence, the story of perceptual awareness cannot have a structure analogous to that of testimonial awareness. A long philosophical tradition has shown how little hope there is for a theory that tries to build awareness of mind-independent particulars out of independent awareness of something mind-dependent. If Schellenberg attempts to rely on the analogy with how we grasp demonstrative singular content in motivating her theory, then she is forced to adopt an explanation of our awareness of mindindependent particulars that has this form. Something must be added to the fact that the world seems to me as if a general condition obtains, if the fact that the world seems this way is to partly explain my awareness of specific mind-independent particulars. However, it is quite obscure what feature internal to the subject's perspective that could be added when we are dealing with our most basic form of awareness of mind-independent particulars; namely perception.

A final option is to argue that it is further features external to the viewpoint of the subject which explains how the subject can be aware of specific particulars by having it seem to her as if the world is such that a general condition obtains. Schellenberg could argue the following: When I exercise my perceptual capacities, the world seems to me as if some particular white cup is singled out (notice this is a general condition as opposed to the singular condition where it seems to me as if cup $\alpha$ is white). When, as a matter of external fact, the conditions are conducive to the success of my discriminatory selective perceptual capacities, then there is indeed specific white cup that is singled out, which forms the referent of the content of my perceptual state. Hence, the world is as it seems to me precisely because conditions are such that I am in a perceptual state with singular content. Schellenberg might argue that the awareness afforded by being in the perceptual state with singular content, is only possible because it is combined with being in the appropriately related state of seeming. However, on closer scrutiny, this account merely leaves it mysterious how the mere fact that certain external conditions obtain should alter 
what I am aware of, when the singular content enabled by these conditions isn't reflected in how the world seems to me. On this account, a perceiver is roughly in the same position as Lenard who stands blind folded in a circle of people and while pointing says 'You get to buy the car'. He has expressed a demonstrative statement that has singular content, since its conditions for successful singular reference were fulfilled. In the given case, Lenard might even have independent knowledge that they are fulfilled, as he knows that he is surrounded by eager buyers; something that is lacking in the perceptual case, since we have no independent means of knowing that we aren't hallucinating. However, Lenard surely isn't aware of which specific individual he has given permission to buy the car. All he is aware of is the general fact that he has given permission to some specific person. Likewise, if Schellenberg's story is simply that how the world seems to me is determined by the occurrence of an experiential state with a singular gappy content-schema, then the mere fact that a given experiential state in fact manages to have singular content because conditions are benevolent won't make a difference to what I am aware off. At least she leaves it utterly mysterious how it could do so, and that is equivalent to providing no account of how the fact that things seem to me a certain way enable my perceptual awareness and my possession of factive experiential evidence. Hence, none of the options available to Schellenberg look promising.

The problem is that once we install a difference between the conditions under which the world is at it seems to me and the conditions that I am perceptually aware of, then it is impossible to retain a proper explanatory role for how the world seems to me in explaining that awareness. However, Schellenberg is forced to install such a difference if she wants to conserve the Same Content Intuitions. She must provide some account of how the world is when it is as it seems to me; where this way of being cannot rely on how things are with a specific particular. And as we saw, referring to the role of potentially gappy content-schemas, rather than proper contents, cannot give an explanation, for a content-schema doesn't settle a way the world can be, as they aren't truth-evaluable. A general content that has a proper relation to the instantiation of a content-schema might do the job of explaining how the world seems to me when that is a way of seeming that is shared by hallucinations and perceptions. However, this means that Schellenberg cannot satisfy the Singular Content Intuition. For this intuition says that we are perceptually aware of how things are with specific particulars, and an adequate theory of perception cannot afford to introduce such a difference between the conditions that I am perceptually aware of and the conditions the world must be in when it is as it seems to me.

\section{Conclusion}

Any adequate theory of perception must account for how my perceptual awareness is explained in terms of the fact that the world seems to me a certain way. On a representational account, the most promising way of doing so is by making the conditions that specify how the world must be in order to be as it seems to me match the truth-conditions of the content that accounts for what I am aware of. This also 
enables one to explain the extent of experiential evidence provided by such experiences in terms of relations between the truth-conditions of judgements and the truth-conditions of perceptual contents. However, doing so forces one to either conserve the Same Content Intuition or the Singular Content Intuition. Schellenberg attempts to conserve both intuitions. Her plan is to explain Same Content Intuition in terms of the potentially gappy singular content-schemas that are shared by both perceptions and indistinguishable hallucination, and explain the Singular Content Intuition in terms of the fully truth-evaluable singular content of perception. However, she is faced with the challenge that content-schemas aren't truth evaluable, and we cannot make any sense of how such non-truth-evaluable contentschemas could on their own account for how the world seems to me and what phenomenal evidence I acquire. Schellenberg relies on an analogy with how demonstrative content figures in testimony in explaining the role of contentschemas. However, once this analogy is fully investigated, we see that her account only works by characterizing how the world seems to me and the phenomenal evidence I possess in terms of some form of general contents.

Schellenberg is faced with the challenge of explaining what role is played by the world seeming a certain way to me in enabling my perceptual awareness of specific particulars. Only if she can account for this will she have managed to also conserve the Singular Content Intuition. However, the fact that the world seems to me as it would be if a general content were true cannot function significantly in an account of what enables my awareness that the world is such that a singular content is true. This structure works in the case of our grasp of the singular content of demonstrative statements, but that is solely because testimonial awareness is not the most basic awareness we have of mind-independent particulars. Hence, Schellenberg's introduction of the notion of potentially gappy singular contentschemas won't enable a representational theory of perception to both conserve the Same Content and the Singular Content Intuitions.

Acknowledgements Open access funding provided by University of Vienna.

Open Access This article is distributed under the terms of the Creative Commons Attribution 4.0 International License (http://creativecommons.org/licenses/by/4.0/), which permits unrestricted use, distribution, and reproduction in any medium, provided you give appropriate credit to the original author(s) and the source, provide a link to the Creative Commons license, and indicate if changes were made.

\section{References}

Block, N. (1995). On a confusion about a function of consciousness. Behavioral and Brain Sciences, 18, 227-287.

Brewer, B. (1999). Perception and reason. Oxford: Oxford University Press.

Brewer, B. (2006). Perception and content. European Journal of Philosophy, 14, 165-181.

Brewer, B. (2011). Perception and its objects. Oxford: Oxford University Press.

Byrne, A. (2001). Intentionalism defended. The Philosophical Review, 110, 199-240.

Byrne, A. (2009). Experience and content. Philosophical Quarterly, 59, 429-451.

Campbell, J. (2002). Reference and consciousness. Oxford: Oxford University Press. 
Crane, T. (2003). The intentional structure of consciousness. In A. Jokic \& Q. Smith (Eds.), New philosophical perspectives (pp. 33-56). Oxford: Oxford University Press.

Dretske, F. (1995). Naturalizing the mind. Cambridge, MA: The MIT Press.

Evans, G. (1982). Varieties of reference. Oxford: Oxford University Press.

Fish, W. (2009). Perception, hallucination, and illusion. New York: Oxford University Press.

Frege, G. (1884/1974). The foundations of arithmetic. Oxford: Basil Blackwell.

Johnston, M. (2006). Better than mere knowledge? The function of sensory awareness. In T. Gendler \& J. Hawthorne (Eds.), Perceptual experience (pp. 260-290). Oxford: Oxford University Press.

Kalderon, M. (2011). Before the law. Philosophical issues, 21, 219-244.

Kaplan, D. (1989). Demonstratives. In J. Almog, J. Perry, \& H. Wettstein (Eds.), Themes from kaplan (pp. 481-563). Oxford: Oxford University Press.

Martin, M. (2002). The transparency of experience. Mind and Language, 17, 376-425.

McDowell, J. (1984). De re senses. The Philosophical Quarterly, 34, 283-294.

McDowell, J. (1986). Singular thought and the extent of inner space. In J. McDowell \& P. Pettit (Eds.), Subject, thought, and context. Oxford: Clarendon Press.

McDowell, J. (1996). Mind and world. Cambridge, MA: Harvard University Press.

McGinn, C. (1982). The character of mind. Oxford: Oxford University Press.

McGrath, M. (2016). Schellenberg on the epistemic force of experience. Philosophical Studies, 173, 897-905.

Neta, R. (2016). Perceptual evidence and the capacity view. Philosophical Studies, 173, 907-914.

Peacocke, C. (1983). Sense and content. Oxford: Oxford University Press.

Perry, John. (1977). Frege on demonstratives. Philosophical Review, 86, 474-497.

Schellenberg, S. (2011). Perceptual content defended. Noûs, 45, 714-750.

Schellenberg, S. (2013a). Externalism and the gappy content of hallucination. In F. Macpherson \& D. Platchias (Eds.), Hallucination (pp. 291-311). Cambridge: MIT Press.

Schellenberg, S. (2013b). Experience and evidence. Mind, 122, 699-747.

Schellenberg, S. (2016a). Phenomenal evidence and factive evidence. Philosophical Studies, 173, 875-896.

Schellenberg, S. (2016b). Phenomenal evidence and factive evidence defended: Replies to McGrath, Pautz, and Neta. Philosophical Studies, 173, 929-946.

Searle, J. (1983). Intentionality: An essay in the philosophy of mind. Cambridge: Cambridge University Press.

Siegel, S. (2010). Do visual experiences have content? In B. Nanay (Ed.), Perceiving the World. Oxford: Oxford University Press.

Siegel, S., \& Silins, N. (2013). The Epistemology of perception. In M. Matthen (Ed.), Oxford handbook of the philosophy of perception. Oxford: Oxford University Press.

Smithies, D. (2011). What is the role of consciousness in demonstrative thought? The Journal of Philosophy, 108(1), 5-34.

Travis, C. (2004). Silence of the Senses. Mind, 113, 57-94.

Travis, C (Forthcoming). 'The move, the divide, the myth and its dogma'. In J. Gersel, R. T. Jensen, M. T. Sørensen \& S. Overgaard (Ed.), In the light of experience-essays on reasons and perception. Oxford: Oxford University Press.

Tye, M. (1995). Ten problems of consciousness. Cambridge, MA: The MIT Press.

Tye, M. (2000). Consciousness, color, and content. Cambridge, MA: The MIT Press.

Tye, M. (2007). Intentionalism and the argument from no common content. Philosophical Perspectives, 21(1), 589-613. 